\title{
sciendo
}

Current Issues in Pharmacy and Medical Sciences

Former ly ANNALES UNIVERSITATIS MARIAE CURIE-SKLODOWSKA, SECTIO DDD, PHARMACIA

\section{The role of tumor-derived exosomes in tumor angiogenesis and tumor progression}

\author{
Alicja Gluszko ${ }^{1}$, Shafaq M. Mirza ${ }^{1}$, Katarzyna Piszczatowska ${ }^{1}$, \\ Ireneusz Kantor ${ }^{2}$, Marta Struga ${ }^{1}$, Miroslaw J. SzCZEPANSKi ${ }^{1,2 *}$ (i) \\ ${ }^{1}$ Chair and Department of Biochemistry, Medical University of Warsaw, Poland \\ 2 Department of Otolaryngology, Centre of Postgraduate Medical Education, Warsaw, Poland
}

\section{ARTICLE INFO \\ Received 14 January 2019 \\ Accepted 22 May 2019}

\section{Keywords:}

tumor-derived exosomes,

angiogenesis,

endothelial cells,

hypoxia.

\begin{abstract}
Exosomes, belonging to the group of extracellular bodies, are released by healthy as well as cancerous cells and serve as a communication pathway. Tumor-derived exosomes (TEX) possess the capacity to reprogram the function of normal cells owing to their genetic and molecular cargo. Such exosomes target endothelial cells (among others) in the tumor microenvironment to promote angiogenesis. Blood supply is essential in solid tumor growth and metastasis. The potential of pro-angiogenic changes is enhanced by an increased amount of circulating tumor-derived exosomes in the body fluids of cancer patients. A vascular network is important, since the proliferation, as well as the metastatic spread of cancer cells depends on an adequate supply of oxygen and nutrients, and the removal of waste products. New blood vessels and lymphatic vessels are formed through processes called angiogenesis and lymphangiogenesis, respectively. Angiogenesis is regulated by both activator and inhibitor molecules. Thousands of patients have received anti-angiogenic therapy to date. Despite their theoretical efficacy, anti-angiogenic treatments have not proved beneficial in terms of long-term survival. Tumor-derived exosomes carrying pro-angiogenic factors might be a target for new anti-cancer therapy.
\end{abstract}

\section{INTRODUCTION}

Exosomes, small membrane vesicles $(30-100 \mathrm{~nm})$ with a cup-shaped morphology, are of endosomal origin. Exosomes represent the smallest of the extracellular vesicles (EVs), which are released by cells and differentiated with regards to size into large, medium and small [1] (Figure 1). Their formation begins with the invagination of the cell membrane to form endosomes, followed by the creation of multivesicular bodies (MVBs) (Figure 2). The fusion of MVBs with the plasma membrane releases the internal vesicles, called exosomes [2-4]. Studies indicate that exosomes can be released by nearly all living cells in the body, including stem cells, platelets, cardiomyocytes, endothelial cells, dendritic cells, B lymphocytes, and tumor cell lines, among others [5-10]. Exosomes contain cargo, including functional microRNAs/RNAs, proteins and lipids, which they deliver to other cells, providing means for a new way of cell-to-cell communication [11-14]. Components present in exosomes can also help modify the functions of different cells, such as angiogenesis. In the process of angiogenesis, new capillaries are created from existing vasculature, which is regulated according to the balance between pro- and antiangiogenic stimuli [15-17]. Although exosomal release is a normal cellular process, an increase in its rate and its differential cargo protein expression are favorable for oncogenic progression and metastasis [11,18]. Exosomes can be collected from blood, plasma, amniotic fluid, saliva, urine, etc., by ultracentrifugation or mini-SEC and assessed for molecular components such as DNA, RNA, miRNA, and proteins [19]. Angiogenesis is an important element in tumor growth and metastasis. For solid tumors, adequate blood supply is of critical importance for their development. The formation of new vasculature in the tumor microenvironment is encouraged by TEX, which accumulate in the tumor microenvironment (TME) [20]. Factors inducing angiogenesis and lymphangiogenesis are receiving increasing attention, especially in the field of neoplastic vascularization [21].

\footnotetext{
* Corresponding author

e-mail: mszczepanski@wum.edu.pl
} 


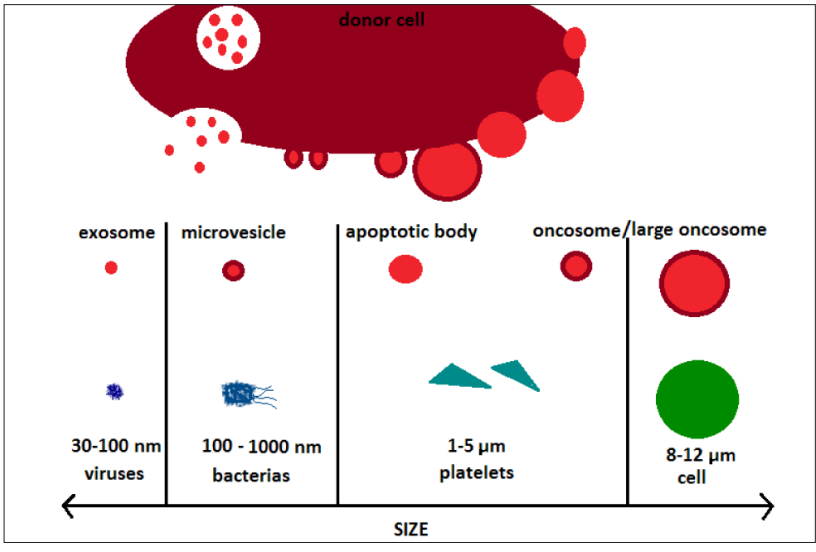

Extracellular vesicles (EVs) represent the particles shed from cells into the extracellular environment. Their diameters range from $30 \mathrm{~nm}$ to $100 \mathrm{~nm}$ [1] (modified)

Figure 1. Vesicles ranking in size

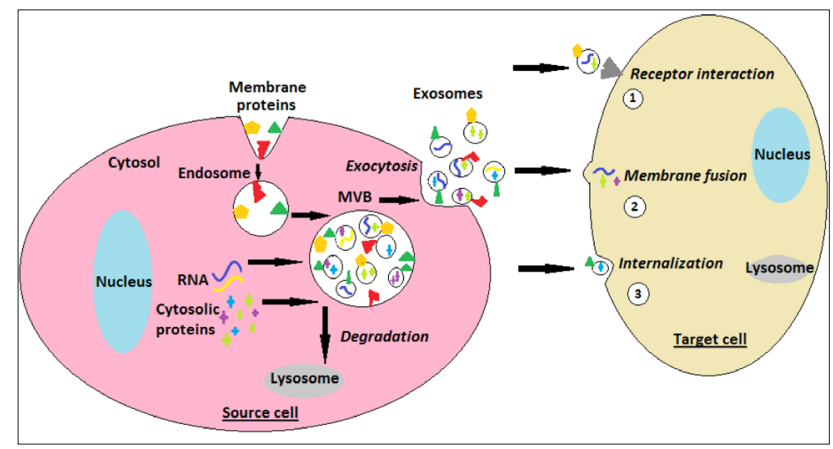

Graphic presentations involve:

- exosomes biogenesis, followed by invagination of cell membrane forming endosomes and sequentially, multivesicular bodies (MVBs)

exosomes secretion, with fusion of MVBs with cell membrane leading to exocytosis of exosomes to extracellular space,

exosomes uptake, with three mechanisms of interactions between secreted exosomes and with target cell:

1) interaction of exosomes membrane proteins with receptor of target cell; 2) fusion of exosomes membrane with acceptor cell membrane;

3) internalization of exosomes structure with acceptor cell through

endocytosis $[30,168-172]$ (modified)

Figure 2. Exosomes life cycle

\section{MECHANISM OF ANGIOGENESIS/VASCULATURE IN TUMOR MICROENVIRONMENT}

Angiogenesis and lymphangiogenesis are the processes where new blood and lymphatic vessels, respectively, are formed. Neovascularization, involving tumor angiogenesis, consists of the following steps: protease production, endothelial cell proliferation and migration, vascular tube formation, anastomosis of newly formed tubes, synthesis of a new basement membrane, and incorporation of pericytes and smooth muscle cells. In the first step, the tissue basement membrane is locally destroyed by proteases, which immediately creates a hypoxic environment. Angiogenic factors start to activate endothelial cells (ECs) to migrate. After the activation of ECs by angiogenic stimuli, proteolytic enzymes are produced, that degrade the perivascular extracellular matrix (ECM) and the rest of the basement membrane. Subsequently, the ECs proliferate and migrate into the perivascular area, forming "primary sprouts", followed by the synthesis of a new basement membrane, tube-like structures formation, blood vessel maturation and complete capillary loops, through which blood can flow [21-23].

The new vasculature in the tumor microenvironment is structurally and functionally abnormal compared to normal blood vessels [21], which contributes to the heterogeneity in tumor blood flow. The tumor blood vessels are immature and leaky [24], characterized by smaller diameter [24-27], more permeability [24,26-28] with lack of or a detached pericyte and basement membrane [24,26,29], heterogeneous vascular density [24-26], and nearly equal microvascular and interstitial fluid pressure $[24,28,30]$. In addition, fast proliferating cancer cells compress intratumoral blood and lymphatic vessels, and as a result, generate pressure and lead to abnormalities in the microenvironment such as impaired blood supply, interstitial hypertension, hypoxia and acidosis [31].

\section{ANGIOGENIC FACTORS}

Vascular endothelial cells divide about every 1000 days on average [32]. In growing cancers, endothelial cells are vigorously active because of the release of many angiogenic factors [22]. Angiogenesis is regulated by both activator and inhibitor molecules. However, angiogenesis in neoplasms is characterized by both up-regulation of the activators as well as down-regulation of the negative regulators of vessel growth [33]. Stimulating factors involve proteins, such as epidermal growth factor (EGF), estrogen, basic and acidic fibroblast growth factor (FGF), interleukin 8 (IL-8), prostaglandin $\mathrm{E} 1$ and $\mathrm{E} 2$, tumor necrosis factor $\alpha(\mathrm{TNF}-\alpha)$, angiogenin, transforming growth factor (TGF- $\alpha$ ), TGF- $\beta$, platelet-derived endothelial growth factor (PDGF), granulocyte colony-stimulating factor (G-CSF), placental growth factor (PGF), hepatocyte growth factor (HGF) and vascular endothelial growth factor (VEGF), which can activate ECs growth and motility. VEGF and bFGF are particularly important in tumor angiogenesis $[21,22]$.

The VEGF family and their receptors (VEGFR) are powerful angiogenic agents in neoplastic tissues, as well as in normal tissues [34-36]. Some angiogenic states can be triggered by hypoxia resulting from the increasing distance between the growing tumor cells and the host capillaries or from the inefficiency of new vessels. Hypoxia induces the expression of VEGF and its receptor via hypoxia-inducible factor- $1 \alpha(\mathrm{HIF}-1 \alpha)$ [37]. The binding of VEGF to its receptor activates proteins relay, that transmit a signal into the nucleus of the endothelial cell. The nuclear signal prompts a group of genes to manufacture the products required for new endothelial cell growth. ECs activated by VEGF produce matrix metalloproteinases (MMPs). The MMPs break down the ECM that fills the spaces between cells and is made up of proteins and polysaccharides. This matrix permits the migration of ECs. The ECs begin to divide as they migrate into the surrounding tissues. Soon they organize themselves into hollow tubes that evolve gradually into a mature network of blood vessels with the help of an adhesion factor, such as integrin $\alpha$ or $\beta[38,39]$. Newly formed blood vessels need to be stabilized to mature. Angiotensin-1, -2 , and their receptor Tie-2 can stabilize and govern vascular growth [40-42].

On the immunohistochemical examination, the VEGF family and their receptors were found to be expressed in about half of the investigated human cancers [43]. These studies also indicated, that the levels of angiogenic factors in tissue reflect the aggressiveness with which tumor cells 
spread, and thus have a predictive value in the identification of high-risk patients with poor prognosis [44-63]. It was also reported that physiological concentrations of thyroid hormone are pro-angiogenic by multiple mechanisms. This increases the possibility that the thyroid hormone (thyroxine) is a case of a non-protein stimulator of angiogenesis that may contribute to clinical resistance to anti-angiogenesis drugs [64]. Prostaglandin E2 (PGE2), as a mitogen in epithelial tumor cells, is another example of a non-protein stimulator of angiogenesis in the vascular endothelium. It has been also shown that the overexpression of cyclooxygenase-2 (an enzyme for the conversion of arachidonic acid to prostaglandin $\mathrm{H} 2$ ) is accompanied by enhanced expression and production of angiogenic factors such as VEGF, FGF-2, HIF-1, MMPs, and adhesion receptors of the integrin families. Therefore, it has been determined, that a high output of PGE2 via increased expression of cyclooxygenase-2, causes tumor development $[65,66]$. Furthermore, the $\mathrm{CCN}$ family of matricellular proteins are cytokines linking cells to the extracellular matrix. $\mathrm{CCN} 3$ is pro-angiogenic, while CCN5 is anti-angiogenic [67-70]. Multimerin 2 (MMRN2) has anti-angiogenic potential, and its downmodulation occurs in the context of tumor-associated angiogenesis [71,72].

There are many naturally occurring proteins, that can inhibit angiogenesis [21]. These signals may systematically disrupt blood vessel formation or support the removal of existing vessels. Inhibitors function by acting on several proteins, that have been identified as angiogenic activators [22]. For angiogenesis to proceed, the functions of negative regulators of vessel growth may need to be down-regulated [21]. The inhibitors include naturally occurring factors such as angiostatin, endostatin, interferon, platelet factor 4, thrombospondin, prolactin $16 \mathrm{kd}$ fragment, tissue inhibitor of metalloproteinase-1, -2, and -3, interleukin 1 and interleukin 12, and retinoic acid [73-75]. Angiostatin is composed of one or more fragments of plasminogen [76]. It induces apoptosis in ECs and tumor cells, and inhibits migration, and formation of tubules in ECs $[77,78]$. Immunohistochemical examination of angiostatin-treated tumors indicated a decrease in the expression of mRNA for VEGF and bFGF [79]. Endostatin binds to the receptor in ECs and may block ECs focal adhesion [80,81]. Endostatin also inhibits growth factors (e.g., bFGF and VEGF-A), and induces proliferation and migration of endothelial cells in vitro and in vivo [82-84].

\section{TUMOR MICROENVIRONMENT PROMOTING AN- GIOGENESIS VIA EXOSOMES}

It is well known that angiogenesis is regulated by oxygen supply and stimulated when tumor tissues require the nutrients and oxygen, that are provided by blood vessels [21, $22]$. Oxygen is the key to cell growth or local metastasis, and its level correlates with the metabolism of endothelial or cancer cells $[85,86]$. Oxygen pressure in normal cells is about $40-60 \mathrm{mmHg}$, as opposed to the majority of malignancies, where the level is about $10 \mathrm{mmHg}$ [87]. Oxygen deprivation in the TME is the result of low supply, because of the distance from supporting blood vessels, irregular tumor vascularization and the increasingly high demand from proliferating cancer cells $[88,89]$. This condition of insufficient oxygen supply, called hypoxia, characterizes malignant tumors, and is involved in their aggressiveness and metastasis [90,91]. To monitor oxygen supply, various oxygen-sensing mechanisms are present in ECs and smooth muscle cells (SMCs), such as nicotinamide adenine dinucleotide phosphate (NADPH) oxidases, endothelial nitric oxide synthases (eNOS), and heme-oxygenases [92]. Other oxygen sensors expressed in vascular cells are hypoxiainducible transcription factors (HIFs), the major components of hypoxia signaling pathways [93].

In response to oxygen insufficiency, cancer cells modify the transcription of genes connected with oxygen monitoring mechanisms, especially HIFs [93]. Almost all types of cancer are characterized by the activation of HIFs. HIFs are present in 3 isoforms of the oxygen-sensitive HIF- $\alpha$ (HIF-1 $\alpha$, HIF-2 $\alpha$, or HIF-3 $\alpha$ ), and a constitutively expressed HIF-1 $\beta$ subunit $[94,95]$. The response to hypoxic conditions is through the activation of HIF-dependent signaling pathways, that regulate the expression of genes associated with angiogenesis, epithelial-to-mesenchymal transition (EMT), metastasis and cellular adaptation for survival in hypoxic conditions [96]. Hypoxia also induces an increased release of exosomes from oxygen-deprived tumor cells, in comparison to cells in normoxic conditions, especially in the context of long-term hypoxia [97]. Studies showed, that moderate $\left(1 \% \mathrm{O}_{2}\right)$ and severe $\left(0.1 \% \mathrm{O}_{2}\right)$ hypoxia lead to a significant increase in the number of exosomes, as observed in three different breast cancer cell lines [98]. In addition to the quantitative impact of exosome secretion, hypoxia-induced stress also causes significant changes in the content and function of exosomes [99]. Exosomes also play a major role in the communication between hypoxic tumors and their microenvironments [18]. Hypoxia-induced exosomes cross-talk with surrounding stromal tissues and transfer tumor phenotypes promoting tumor angiogenesis, invasion, metastasis and immune escape [99].

In the context of angiogenesis, hypoxia is a major inductor [18]. Hypoxic exosomes, by alterations in their molecular cargo, modulate tumor-ECs communication, inducing ECs proliferation and tube formation [18] (Figure 3). The expression of different non-coding RNAs delivered by exosomes, such as miR-210, miR135b, miR23a, miR494, is regulated

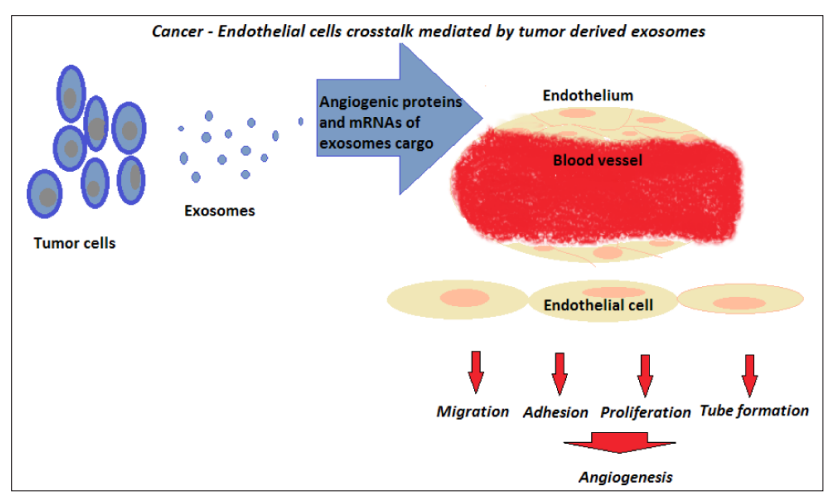

Hypoxic condition in the tumor environment increases the release of tumorderived exosomes (TEX) and is a strong stimuli for the communication between cancer and endothelial cells (ECs). TEX transfer molecular information, which after uptake by ECs, promote their adhesion, proliferation, migration, tube formation, and as a result pathological angiogenesis [20] (modified)

Figure 3. Cancer and endothelial cells cross-talk 
by hypoxia [99]. Research has shown that hypoxic exosomes with miR-210 were released from breast cancer in significant quantities through HIF-1 $\alpha$ activation [98]. Hypoxia induces neutral sphingomyelinase 2 (nSMase2), mediating mRNA sorting in exosomes, and leads to the secretion of miR-210, which plays a role in angiogenesis [100]. In vitro studies present tube formation in human umbilical vein endothelial cells (HUVECs) incubated with hypoxic exosomes rich in miR-210 and released from human leukemic cells [101]. In another study, expression of exosomal miR-135b was significantly higher in hypoxia-resistant multiple myeloma (HR-MM) as compared to normoxic cells [102]. Moreover, this exosomal miR-135b was captured by ECs and enhanced angiogenesis via HIF-1 activation [102].

Targeting prolyl hydroxylase and tight junction protein ZO-1 by exosomal miR23a derived from hypoxic lung cancer cells also stimulates angiogenesis [103]. In exosomal cargo derived from hypoxic lung cancer cells, miR-494 was highly expressed via the HIF-1 $\alpha$-mediated mechanism, following capture by ECs, which in turn down-regulated PTEN and activated the Akt/eNOS pathway [104]. Furthermore, in exosomes released from hypoxic human squamous carcinoma cells, A431 was found to facilitate angiogenesis [105], while hypoxic glioblastoma exosomes were enriched with VEGF [106-110]. Furthermore, hypoxic colorectal cancer exosomes were found to stimulate the proliferation of ECs [111]. Moreover, hypoxic hepatocellular carcinoma [112], and breast cancer cells were seen to induce angiogenesis in vitro and in vivo via miR-23a and miR-210, respectively, while enclosed in their exosomes [98]. In addition, exosomes originating from hypoxic brain tumor glioblastoma multiforme cells were noted to present increased levels of IL-8 and PDGF as angiogenic stimulatory molecules [108].

EVs produced by hypoxic tumor cells have been shown to have a more pronounced effect on ECs in promoting angiogenesis than those derived from normoxic cells [102, 113]. Hypoxia increases the production of tumor and stromal cell-derived EVs, and alters their cargo [98,102,103,114, 115]. For example, miR-23a is found in the EVs of hypoxic, but not normoxic, lung cancer cells [103]. Increased EVs production by hypoxic endothelial cells was abrogated by siRNA targeting hypoxia-inducible factor 1 , thus providing a clear link between cell response to hypoxia and EVs production [114].

The tumor microenvironment consists of cellular and acellular factors and includes ECM, cancer-associated fibroblasts (CAFs), inflammatory immune cells and tumorassociated vasculature [116]. CAFs are important components within the TME that play a key role in tumorigenesis. Analysis with mass spectrometry has identified a plethora of growth factors released by CAFs-derived exosomes such as modulators of epidermal growth factor receptor (EGFR), insulin-like growth factor receptor (IGFR), platelet-derived growth factor receptor (PDGFR), chemokines, cytokines, and matrix metalloproteinases. These factors remodel the ECM significantly and contribute to important hallmarks necessary for cancer progression, such as sustained growth, invasion, inflammation, angiogenesis, metastasis and therapeutic resistance [117-119]. Furthermore, studies demonstrate a correlation between hypoxic conditions and the activation of CAFs-prostate cancer cells with an insufficient oxygen supply, that released exosomes containing nearly three times more protein than that in normoxic conditions, resulting in CAFs induction [120], promotion of EMT, stemness, and angiogenesis [121,122].

\section{MOLECULAR CARGO OF TEX INFLUENCING ANGIOGENESIS / TEX CONVERTING ENDOTHELIAL CELLS}

Endothelial cells belonging to the tumor microenvironment are key components providing a conduit to nutrients, and represent a source of trophic factors [123]. Angiogenesis, a complex and multistep process, consists of proliferation, migration, invasion, adhesion and differentiation of ECs [124]. Various physiological and pathological conditions [125] stimulating vascularization, following tumor growth and metastasis [126], are regulated via the transfer of pro-angiogenic molecules from tumor to endothelial cells by EVs (Figure 2). In a variety of cancer types, EVs have been shown to increase tube formation, migration, cell-cell adhesion and proliferation in ECs [100,102,113, 127-133]. Studies have been performed to determine the relationship between EVs and pathological angiogenesis [134]. It was demonstrated that HUVECs induce pathological angiogenesis [135] via an abundance of genetic information transferred by EVs [136]. In response to TEX uptake by HUVECs, tube formation, proliferation, migration and adherence were observed. TEX were investigated to have the potential to reprogram and induce phenotypic modulation of ECs. Studies indicated that HUVECs internalize TEX carrying angiogenic proteins within 4 hours, stimulating their conversion into vascular structures in vitro [20]. The same results were achieved in in vitro studies with exosomes derived from metastatic tumor cells [100]. Moreover, EVs from nasopharyngeal carcinoma (NPC) cells are enriched with HCLS1-associated protein X-1 (HAX-1) and could accelerate the proliferation and migration of HUVECs [134].

Exosomes also play an instrumental role in tumor-ECs communication [123]. The EVs from tumor cells contain various pro-angiogenic molecules, such as bFGF, VEGF and TGF- $\beta$, that function as stimuli for endothelial cell proliferation and migration $[137,138]$. Activated EGFR found in EVs is sufficient to induce EGFR and VEGFR signaling in recipient endothelial cells [128, 139]. ECs incorporated TEX with cargo such as tetraspanin 8, CD106, and activated VEGFs, resulting in ECs proliferation, migration, sprouting and maturation of ECs progenitors [140]. The endothelial progenitor cells release exosomes that interact with mature ECs, and integration of their cargos trigger AKT signaling, resulting in angiogenesis [141]. Tetraspanins were discussed for their role in exosome biogenesis, cargo sorting, cancer progression, and are suggested to be key players in the process of angiogenesis [142]. Exosomes derived from myeloma and breast cancers demonstrate the presence of Syndecan-1, VEGF and HGF, which lead to increased endothelial invasion through the ECM [143]. Melanoma-derived exosomes were also shown to produce angiogenic growth factors [144]. 
With the aid of exosomes derived from glioma cells, the oncogenic receptor EGFRvIII was transported. This resulted in EGFRvIII-dependent transcription, transforming phenotype and oncogenic activity [139]. Additionally, by delivering Epidermal Growth Factor Receptor (EGFR) [128] and miR-9 to ECs [145], skin cancer-derived exosomes can promote angiogenesis. Exosomes originated from melanoma cells, including miR-9, enhance angiogenesis and metastasis via activation of the JAK-STAT pathway after internalization by ECs [145]. Increased vascularization has been associated with the packaging of CO-029/D6. 1A Tetraspanin in pancreatic cancer-derived exosomes [142], and of miR- 92a in leukemia-derived exosomes which can regulate integrin 5 to promote migration and proliferation of ECs and tube formation [146]. Other EV-derived molecules that have been shown to play a role in promoting angiogenesis include miR-105, miR-142-3p, miR-210 and H19 lncRNA [103, 129-131,133,147,148].

The integrity of vascular barriers is frequently associated with metastatic dissemination. TEX carrying miR-105 are known to destroy vascular endothelial barriers by targeting the tight junctions of ECs and modifying the expression of claudin 5, zonula occludens protein 1, and occludin, thereby promoting metastasis in breast cancer [147]. Brain tumor-derived exosomes containing miR-181c modulate actin in ECs and promote the breakdown of the blood-brain barrier by 3-phosphoinositide-dependent protein kinase-1 degradation [149]. Similarly, exosomes produced by glioblastoma cells containing high levels of VEGF-A induce ECs permeability and angiogenesis in vitro [150]. In the same way, melanoma-derived exosomes induce pulmonary vascular leakiness [151], and upregulate genes related to the tumor cell recruitment, such as stabilin 1, vitronectin, integrins, and ephrin receptor b4 in lymph nodes [144].

Exosomal miR-21 and 29a can act as ligands for toll-like receptors and can induce inflammatory responses during pre-metastatic niche formation [101]. Pre-metastatic niche formation contributes to the metastasis, where progenitors have shown an increased expression of VEGF-1 in target sites and overexpression of fibronectin in resident fibroblast [152].

Another report uncovered the fact that CD-105-positive exosomes possess an important role in establishing a niche in the lung microenvironment of SCID mice through the increased expression of MMP2, MMP9, and VEGFR1 [113]. This suggests there are sub-populations with cell markers indicative of tumor-initiating cells. In related work, the impact of the heterogeneity found within tumors was investigated. In renal cell carcinoma cell lines, CD105-positive cells were found to release EVs that increase proliferation, vessel formation, and invasion in HUVECs, whereas CD105-negative cells did not [113]. Similarly, in liver cancer cells, CD90-positive cells were found to secrete EVs, that promote tube formation and cell-cell adhesion via the transfer of H19 lncRNA [129]. These results suggest, that subsets of tumor cells secrete EVs carrying a unique set of cargo capable of altering stromal cell phenotypes in specific ways [153].

EMT promotion, together with degradation of ECM and cell adhesion junctions between adjacent cells, is conducted by activation of plasminogen and its conversion into plasmin, as triggered by exosomal hsp90, along with annexin-II released to the extracellular sites [154]. Communication between metastatic tumor cells and ECs can activate various cytoskeletal proteins such as RAC1, which regulate endothelial tubular morphology by inducing tubular sprouting and spheroid formation $[155,156]$. Genes related to vascular remodeling, such as ephrin A3 and PTP1B were also reported to be expressed and transferred via exosomes [18].

\section{POTENTIAL OF TEX AS NEW TARGETS IN CANCER}

In general, inhibitors of angiogenesis can be classified into two main groups: direct inhibitors, that target endothelial cells in the growing vasculature, and indirect inhibitors, that target either tumor cells or the other tumor-associated stromal cells [157].

Cytotoxic therapy suppresses cancer directly, while angiogenic therapy suppresses it indirectly by depriving cells of nutrients and oxygen. The use of angiogenesissuppressors and receptor-inhibitors can prohibit the neovascularization of cancer tissue, as well as the growth of the tumor, and thus might be beneficial in the treatment of cancer [21]. During tumor progression, the anti-angiogenic factors' production is reduced, with a simultaneous elevation of pro-angiogenic factors. This helps explain the current suboptimal effectiveness in the oncology of the pharmacological inhibitors of single endogenous angiogenic agents [22]. Moreover, evidence supports the view, that cytotoxic agents and anti-angiogenic agents would destroy both cancer cells and endothelial cells [158]. Abnormal microenvironments characterized by impaired blood supply, interstitial hypertension, hypoxia, and acidosis [31] interfere with the delivery of therapeutic drugs, rendering tumor cells resistant to both radiation and some forms of cytotoxic therapy. These conditions also result in genetic stability and selection for more malignant cells with increased metastatic potential, and compromise the cytotoxic functions of immune cells. This emphasizes the importance of normalizing and regulating tumor vasculature [21]. The adverse reactions of the inhibition of VEGF therapy is decreased production of NO, which will promote vasoconstriction, increase the peripheral resistance, and eventually elevate blood pressure [159]. Under normal conditions, VEGF is known to release vasodilator nitric oxide (NO) in vessel walls by upregulating endothelial nitric oxide synthase and prostacyclin (PGI2), resulting in vasodilation, through the activation of the mitogen-activated protein kinase (MAPK) and phosphatidylinositol 3-kinase (PI3K) downstream pathways [160-163].

The data suggest that TEX promote angiogenesis and drive cancer progression [20]. At the same time, exosomes can be used for drug targeting [18]. Future efforts should focus on eliminating or silencing TEX and thereby adding new options for improving existing anti-angiogenic therapies [20]. Recent approaches involve counteracting the pro-tumorigenic effects of EVs. One of them is to directly remove EVs from circulation. This was conducted by Marleau [164], by using an extracorporeal hemofiltration system to filter blood for components under $200 \mathrm{~nm}$ and then removing them by means of applying affinity agents 
for target molecules. In another investigation, the treatment of mice with anti-CD9 or anti-CD63 antibodies was found to stimulate EVs removal by macrophages, thus greatly decreasing EVs concentration in the blood. Although this treatment had no effect on the primary tumor, the authors observed a significant reduction in metastasis [165]. Blocking EVs biogenesis in tumor cells by silencing genes encoding EV-related machinery is another potential avenue for inhibiting tumorigenesis [130,147,166].

Exosomes can be also engineered to transport a variety of molecules like protein, peptides, drugs, etc. even across the blood-brain barrier without inducing any systemic toxic effects, making them promising candidates for drug delivery. Exosomes have been used for the delivery of various chemotherapeutics and also natural substances like curcumin, resveratrol, etc. Similarly, nanoformulations of other natural drug candidates against pro-angiogenic factors may provide selective inhibition and might also be a promising option [167].

\section{CONCLUSION}

While elaborating on tumor progression, which is tightly connected with neoplastic vascularisation, we have to take into consideration the presence of TEX in TME. The release of tumor - as well as stromal cell-derived exosomes increases in hypoxic conditions, thereby initiating and promoting the angiogenesis process.

Hypoxia-induced TEX cross-talk with surrounding stromal tissues results in the transfer of tumor phenotypes, which, as a consequence, results in tumor angiogenesis, invasion, metastasis and immune escape. In the context of angiogenesis, by the alteration in their molecular cargo, hypoxic TEX reprogram ECs and induce phenotypic modulation of ECs. As a result, increased migration, cell-cell adhesion, proliferation of ECs, and enhanced tubular sprouting, and tube formation is observed. The potential of TEX, as angiogenesis process inducers, make them a target in antiangiogenic therapy. The conducted attempts of eliminating or silencing TEX have resulted in a significant reduction in metastasis. Blocking TEX biogenesis is another potential in decreasing their negative role. Being natural cell transport vehicles, exosomes can be also engineered to transport a variety of molecules, making them promising candidates for drug delivery. These findings provide new insights into the complex cellular and genomic networks and can give new perceptivity into improving existing anti-angiogenic therapies.

\section{LIST OF ABBREVIATIONS}

Mini-SEC - mini size exclusion chromatography; $\mathrm{CCN}$ - family of regulatory proteins (Connective tissue growth factor (CTGF), Cystein rich protein (Cyr61) and Nephroblastoma overexpressed gene (nov));

PTEN - phosphatase and tensin homolog deleted on chromosome ten;

SCID mice - severe combined immunodeficiency mice.

\section{ACKNOWLEDGMENTS}

This work was funded from the National Science Center, Poland 2017/26/M/NZ5/00877\# research grant to M.J.S.

\section{CONFLICT OF INTEREST}

The authors declare that they have no conflict of interest.

\section{ORCID iDs}

Mirosław Szczepański (1) https://orcid.org/0000-0002-5206-137X

\section{REFERENCES}

1. Zaborowski MP, Balaj L, Breakefield XO, Lai CP. Extracellular Vesicles: Composition, Biological Relevance, and Methods of Study. Bioscience. 2015;65(8):783-97.

2. Ribeiro MF, Zhu H, Millard RW, Fan GC. Exosomes Function in Pro- and Anti-Angiogenesis. Curr Angiogenes. 2013;2(1):54-9.

3. Escola JM, Kleijmeer MJ, Stoorvogel W, Griffith JM, Yoshie O, Geuze HJ. Selective enrichment of tetraspan proteins on the internal vesicles of multivesicular endosomes and on exosomes secreted by human B-lymphocytes. J Biol Chem. 1998;273(32):20121-7.

4. Heijnen HF, Schiel AE, Fijnheer R, Geuze HJ, Sixma JJ. Activated platelets release two types of membrane vesicles: microvesicles by surface shedding and exosomes derived from exocytosis of multivesicular bodies and alpha-granules. Blood. 1999;94(11):3791-9.

5. Lai RC, Arslan F, Lee MM, Sze NS, Choo A, Chen TS, et al. Exosome secreted by MSC reduces myocardial ischemia/reperfusion injury. Stem Cell Res. 2010;4(3):214-22.

6. Li QL, Bu N, Yu YC, Hua W, Xin XY. Exvivo experiments of human ovarian cancer ascites-derived exosomes presented by dendritic cells derived from umbilical cord blood for immunotherapy treatment. Clin Med Oncol. 2008;2:461-7.

7. Ma B, Ren J, Jiang HF, Jia J. [Antitumor activities against hepatocellular carcinoma induced by bone marrow mesenchymal stem cells pulsed with tumor-derived exosomes]. Beijing Da Xue Xue Bao Yi Xue Ban. 2008;40(5):494-9.

8. Thery C, Regnault A, Garin J, Wolfers J, Zitvogel L, RicciardiCastagnoli $\mathrm{P}$, et al. Molecular characterization of dendritic cellderived exosomes. Selective accumulation of the heat shock protein hsc73. J Cell Biol. 1999;147(3):599-610.

9. Yu S, Liu C, Su K, Wang J, Liu Y, Zhang L, et al. Tumor exosomes inhibit differentiation of bone marrow dendritic cells. J Immunol. 2007;178(11):6867-75.

10. Zhang X, Wang X, Zhu H, Kranias EG, Tang Y, Peng T, et al. Hsp20 functions as a novel cardiokine in promoting angiogenesis via activation of VEGFR2. PLoS One. 2012;7(3):e32765.

11. Al-Nedawi K, Meehan B, Rak J. Microvesicles: messengers and mediators of tumor progression. Cell Cycle. 2009;8(13):2014-8.

12. Camussi G, Deregibus MC, Bruno S, Cantaluppi V, Biancone L. Exosomes/microvesicles as a mechanism of cell-to-cell communication. Kidney Int. 2010;78(9):838-48.

13. Wieckowski E, Whiteside TL. Human tumor-derived vs dendritic cell-derived exosomes have distinct biologic roles and molecular profiles. Immunol Res. 2006;36(1-3):247-54.

14. Zhu H, Fan GC. Extracellular/circulating microRNAs and their potential role in cardiovascular disease. Am J Cardiovasc Dis. 2011;1(2):138-49.

15. Burnier L, Fontana P, Kwak BR, Angelillo-Scherrer A. Cell-derived microparticles in haemostasis and vascular medicine. Thromb Haemost. 2009;101(3):439-51.

16. Dignat-George F, Boulanger CM. The many faces of endothelial microparticles. Arterioscler Thromb Vasc Biol. 2011;31(1):27-33.

17. Martinez MC, Andriantsitohaina R. Microparticles in angiogenesis: therapeutic potential. Circ Res. 2011;109(1):110-9.

18. Rajagopal C, Harikumar KB. The Origin and Functions of Exosomes in Cancer. Front Oncol. 2018;8:66. 
19. Keller S, Ridinger J, Rupp AK, Janssen JW, Altevogt P. Body fluid derived exosomes as a novel template for clinical diagnostics. J Transl Med. 2011;9:86.

20. Ludwig N, Yerneni SS, Razzo BM, Whiteside TL. Exosomes from HNSCC Promote Angiogenesis through Reprogramming of Endothelial Cells. Mol Cancer Res. 2018;16(11):1798-808.

21. Nishida N, Yano H, Nishida T, Kamura T, Kojiro M. Angiogenesis in cancer. Vasc Health Risk Manag. 2006;2(3):213-9.

22. Rajabi M, Mousa SA. The Role of Angiogenesis in Cancer Treatment. Biomedicines. 2017;5(2).

23. Koch AE, Distler O. Vasculopathy and disordered angiogenesis in selected rheumatic diseases: rheumatoid arthritis and systemic sclerosis. Arthritis Res Ther. 2007;9 Suppl 2:S3.

24. Tong RT, Boucher Y, Kozin SV, Winkler F, Hicklin DJ, Jain RK. Vascular normalization by vascular endothelial growth factor receptor 2 blockade induces a pressure gradient across the vasculature and improves drug penetration in tumors. Cancer Res. 2004;64(11):3731-6.

25. Izumi Y, Xu L, di Tomaso E, Fukumura D, Jain RK. Tumour biology: herceptin acts as an anti-angiogenic cocktail. Nature. 2002;416(6878):279-80.

26. Winkler F, Kozin SV, Tong RT, Chae SS, Booth MF, Garkavtsev I, et al. Kinetics of vascular normalization by VEGFR2 blockade governs brain tumor response to radiation: role of oxygenation, angiopoietin-1, and matrix metalloproteinases. Cancer Cell. 2004;6(6):553-63.

27. Yuan F, Chen Y, Dellian M, Safabakhsh N, Ferrara N, Jain RK. Time-dependent vascular regression and permeability changes in established human tumor xenografts induced by an anti-vascular endothelial growth factor/vascular permeability factor antibody. Proc Natl Acad Sci U S A. 1996;93(25):14765-70.

28. Willett CG, Boucher Y, di Tomaso E, Duda DG, Munn LL, Tong RT, et al. Direct evidence that the VEGF-specific antibody bevacizumab has antivascular effects in human rectal cancer. Nat Med. 2004;10(2):145-7.

29. Inai T, Mancuso M, Hashizume H, Baffert F, Haskell A, Baluk P, et al. Inhibition of vascular endothelial growth factor (VEGF) signaling in cancer causes loss of endothelial fenestrations, regression of tumor vessels, and appearance of basement membrane ghosts. Am J Pathol. 2004;165(1):35-52.

30. Lee Y, El Andaloussi S, Wood MJ. Exosomes and microvesicles: extracellular vesicles for genetic information transfer and gene therapy. Hum Mol Genet. 2012;21(R1):R125-34.

31. Padera TP, Stoll BR, Tooredman JB, Capen D, di Tomaso E, Jain RK. Pathology: cancer cells compress intratumour vessels. Nature. 2004;427(6976):695.

32. Denekamp J. Review article: angiogenesis, neovascular proliferation and vascular pathophysiology as targets for cancer therapy. $\mathrm{Br} J$ Radiol. 1993;66(783):181-96.

33. Dameron KM, Volpert OV, Tainsky MA, Bouck N. Control of angiogenesis in fibroblasts by 553 regulation of thrombospondin-1. Science. 1994;265(5178):1582-4.

34. Folkman J. What is the evidence that tumors are angiogenesis dependent? J Natl Cancer Inst. 1990;82(1):4-6.

35. Folkman J. Angiogenesis in cancer, vascular, rheumatoid and other disease. Nat Med. 1995;1(1):27-31.

36. Folkman J. Seminars in Medicine of the Beth Israel Hospital, Boston. Clinical applications of research on angiogenesis. N Engl J Med. 1995;333(26):1757-63.

37. Bottaro DP, Liotta LA. Cancer: Out of air is not out of action. Nature. 2003;423(6940):593-5.

38. Mizejewski GJ. Role of integrins in cancer: survey of expression patterns. Proc Soc Exp Biol Med. 1999;222(2):124-38.

39. Nelson AR, Fingleton B, Rothenberg ML, Matrisian LM. Matrix metalloproteinases: biologic activity and clinical implications. J Clin Oncol. 2000;18(5):1135-49.

40. Maisonpierre PC, Suri C, Jones PF, Bartunkova S, Wiegand SJ, Radziejewski C, et al. Angiopoietin-2, a natural antagonist for Tie2 that disrupts in vivo angiogenesis. Science. 1997;277(5322):55-60.

41. Suri C, Jones PF, Patan S, Bartunkova S, Maisonpierre PC, Davis S, et al. Requisite role of angiopoietin-1, a ligand for the TIE2 receptor, during embryonic angiogenesis. Cell. 1996;87(7):1171-80.
42. Tournaire R, Simon MP, le Noble F, Eichmann A, England P, Pouyssegur J. A short synthetic peptide inhibits signal transduction, migration and angiogenesis mediated by Tie2 receptor. EMBO Rep. 2004;5(3):262-7.

43. Salven P, Lymboussaki A, Heikkila P, Jaaskela-Saari H, Enholm B, Aase K, et al. Vascular endothelial growth factors VEGF-B and VEGF-C are expressed in human tumors. Am J Pathol. 1998;153(1): 103-8.

44. Amioka T, Kitadai Y, Tanaka S, Haruma K, Yoshihara M, Yasui W, et al. Vascular endothelial growth factor-C expression predicts lymph node metastasis of human gastric carcinomas invading the submucosa. Eur J Cancer. 2002;38(10):1413-9.

45. Andre T, Kotelevets L, Vaillant JC, Coudray AM, Weber L, Prevot S, et al. Vegf, Vegf-B, Vegf-C and their receptors KDR, FLT-1 and FLT-4 during the neoplastic progression of human colonic mucosa. Int $J$ Cancer. 2000;86(2):174-81.

46. Boocock CA, Charnock-Jones DS, Sharkey AM, McLaren J, Barker PJ, Wright KA, et al. Expression of vascular endothelial growth factor and its receptors flt and KDR in ovarian carcinoma. J Natl Cancer Inst. 1995;87(7):506-16.

47. Decaussin M, Sartelet H, Robert C, Moro D, Claraz C, Brambilla C, et al. Expression of vascular endothelial growth factor (VEGF) and its two receptors (VEGF-R1-Flt1 and VEGF-R2-Flk1/KDR) in nonsmall cell lung carcinomas (NSCLCs): correlation with angiogenesis and survival. J Pathol. 1999;188(4):369-77.

48. Furudoi A, Tanaka S, Haruma K, Kitadai Y, Yoshihara M, Chayama K, et al. Clinical significance of vascular endothelial growth factor $\mathrm{C}$ expression and angiogenesis at the deepest invasive site of advanced colorectal carcinoma. Oncology. 2002;62(2):157-66.

49. George ML, Tutton MG, Janssen F, Arnaout A, Abulafi AM, Eccles SA, et al. VEGF-A, VEGF-C, and VEGF-D in colorectal cancer progression. Neoplasia. 2001;3(5):420-7.

50. Gunningham SP, Currie MJ, Han C, Robinson BA, Scott PA, Harris AL, et al. The short form of the alternatively spliced flt- 4 but not its ligand vascular endothelial growth factor $\mathrm{C}$ is related to lymph node metastasis in human breast cancers. Clin Cancer Res. 2000;6(11):4278-86.

51. Hashimoto I, Kodama J, Seki N, Hongo A, Yoshinouchi M, Okuda $\mathrm{H}$, et al. Vascular endothelial growth factor-C expression and its relationship to pelvic lymph node status in invasive cervical cancer. Br J Cancer. 2001;85(1):93-7.

52. Hirai M, Nakagawara A, Oosaki T, Hayashi Y, Hirono M, Yoshihara T. Expression of vascular endothelial growth factors (VEGF-A/VEGF-1 and VEGF-C/VEGF-2) in postmenopausal uterine endometrial carcinoma. Gynecol Oncol. 2001;80(2):181-8.

53. Jussila L, Valtola R, Partanen TA, Salven P, Heikkila P, Matikainen MT, et al. Lymphatic endothelium and Kaposi's sarcoma spindle cells detected by antibodies against the vascular endothelial growth factor receptor-3. Cancer Res. 1998;58(8):1599-604.

54. Kinoshita J, Kitamura K, Kabashima A, Saeki H, Tanaka S, Sugimachi K. Clinical significance of vascular endothelial growth factor-C (VEGF-C) in breast cancer. Breast Cancer Res Treat. 2001;66(2):159-64

55. Kurebayashi J, Otsuki T, Kunisue H, Mikami Y, Tanaka K, Yamamoto S, et al. Expression of vascular endothelial growth factor (VEGF) family members in breast cancer. Jpn J Cancer Res. 1999;90(9):977-81.

56. Niki T, Iba S, Tokunou M, Yamada T, Matsuno Y, Hirohashi S. Expression of vascular endothelial growth factors A, B, C, and D and their relationships to lymph node status in lung adenocarcinoma. Clin Cancer Res. 2000;6(6):2431-9.

57. Nishida N, Yano H, Komai K, Nishida T, Kamura T, Kojiro M. Vascular endothelial growth factor $\mathrm{C}$ and vascular endothelial growth factor receptor 2 are related closely to the prognosis of patients with ovarian carcinoma. Cancer. 2004;101(6):1364-74.

58. Ohta Y, Shridhar V, Bright RK, Kalemkerian GP, Du W, Carbone M, et al. VEGF and VEGF type C play an important role in angiogenesis and lymphangiogenesis in human malignant mesothelioma tumours. Br J Cancer. 1999;81(1):54-61. 
59. O-charoenrat P, Rhys-Evans P, Eccles SA. Expression of vascular endothelial growth factor family members in head and neck squamous cell carcinoma correlates with lymph node metastasis. Cancer. 2001;92(3):556-68.

60. Skobe M, Hawighorst T, Jackson DG, Prevo R, Janes L, Velasco P, et al. Induction of tumor lymphangiogenesis by VEGF-C promotes breast cancer metastasis. Nat Med. 2001;7(2):192-8.

61. Yokoyama Y, Charnock-Jones DS, Licence D, Yanaihara A, Hastings JM, Holland CM, et al. Vascular endothelial growth factor-D is an independent prognostic factor in epithelial ovarian carcinoma. Br J Cancer. 2003;88(2):237-44.

62. Yonemura Y, Endo Y, Fujita H, Fushida S, Ninomiya I, Bandou E, et al. Role of vascular endothelial growth factor $\mathrm{C}$ expression in the development of lymph node metastasis in gastric cancer. Clin Cancer Res. 1999;5(7):1823-9.

63. Kajita T, Ohta Y, Kimura K, Tamura M, Tanaka Y, Tsunezuka Y, et al. The expression of vascular endothelial growth factor $\mathrm{C}$ and its receptors in non-small cell lung cancer. Br J Cancer. 2001; 85(2):255-60.

64. Mousa SA, Lin HY, Tang HY, Hercbergs A, Luidens MK, Davis PJ. Modulation of angiogenesis by thyroid hormone and hormone analogues: implications for cancer management. Angiogenesis. 2014;17(3):463-9.

65. Finetti F, Solito R, Morbidelli L, Giachetti A, Ziche M, Donnini S. Prostaglandin E2 regulates angiogenesis via activation of fibroblast growth factor receptor-1. J Biol Chem. 2008;283(4):2139-46.

66. Xu L, Stevens J, Hilton MB, Seaman S, Conrads TP, Veenstra TD, et al. COX-2 inhibition potentiates antiangiogenic cancer therapy and prevents metastasis in preclinical models. Sci Transl Med. 2014; 6(242):242ra84.

67. Butler GS, Connor AR, Sounni NE, Eckhard U, Morrison CJ, Noel A, et al. Degradomic and yeast 2-hybrid inactive catalytic domain substrate trapping identifies new membrane-type 1 matrix metalloproteinase (MMP14) substrates: CCN3 (Nov) and CCN5 (WISP2). Matrix Biol. 2017;59:23-38.

68. Chen PC, Cheng HC, Wang J, Wang SW, Tai HC, Lin CW, et al. Prostate cancer-derived CCN3 induces M2 macrophage infiltration and contributes to angiogenesis in prostate cancer microenvironment. Oncotarget. 2014;5(6):1595-608.

69. Lin Z, Natesan V, Shi H, Hamik A, Kawanami D, Hao C, et al. A novel role of CCN3 in regulating endothelial inflammation. J Cell Commun Signal. 2010;4(3):141-53.

70. Zhang C, van der Voort D, Shi H, Zhang R, Qing Y, Hiraoka S, et al. Matricellular protein CCN3 mitigates abdominal aortic aneurysm. J Clin Invest. 2016;126(4):1282-99.

71. Andreuzzi E, Colladel R, Pellicani R, Tarticchio G, Cannizzaro R, Spessotto $\mathrm{P}$, et al. The angiostatic molecule Multimerin 2 is processed by MMP-9 to allow sprouting angiogenesis. Matrix Biol. 2017;64:40-53

72. Colladel R, Pellicani R, Andreuzzi E, Paulitti A, Tarticchio G, Todaro F, et al. MULTIMERIN2 binds VEGF-A primarily via the carbohydrate chains exerting an angiostatic function and impairing tumor growth. Oncotarget. 2016;7(2):2022-37.

73. Ali SH, O’Donnell AL, Balu D, Pohl MB, Seyler MJ, Mohamed S, et al. Estrogen receptor-alpha in the inhibition of cancer growth and angiogenesis. Cancer Res. 2000;60(24):7094-8.

74. Kerbel RS. Tumor angiogenesis. N Engl J Med. 2008;358(19):2039-49.

75. Pavlakovic H, Havers W, Schweigerer L. Multiple angiogenesis stimulators in a single malignancy: implications for anti-angiogenic tumour therapy. Angiogenesis. 2001;4(4):259-62.

76. Stack MS, Gately S, Bafetti LM, Enghild JJ, Soff GA. Angiostatin inhibits endothelial and melanoma cellular invasion by blocking matrix-enhanced plasminogen activation. Biochem J. 1999;340 (Pt 1):77-84.

77. Claesson-Welsh L, Welsh M, Ito N, Anand-Apte B, Soker S, Zetter B, et al. Angiostatin induces endothelial cell apoptosis and activation of focal adhesion kinase independently of the integrin-binding motif RGD. Proc Natl Acad Sci U S A. 1998;95(10):5579-83.

78. Lucas R, Holmgren L, Garcia I, Jimenez B, Mandriota SJ, Borlat F, et al. Multiple forms of angiostatin induce apoptosis in endothelial cells. Blood. 1998;92(12):4730-41.
79. Kirsch M, Strasser J, Allende R, Bello L, Zhang J, Black PM. Angiostatin suppresses malignant glioma growth in vivo. Cancer Res. 1998;58(20):4654-9.

80. Rehn M, Veikkola T, Kukk-Valdre E, Nakamura H, Ilmonen $\mathrm{M}$, Lombardo C, et al. Interaction of endostatin with integrins implicated in angiogenesis. Proc Natl Acad Sci U S A. 2001;98(3): 1024-9.

81. Wickstrom SA, Alitalo K, Keski-Oja J. Endostatin associates with integrin alpha5betal and caveolin-1, and activates Src via a tyrosyl phosphatase-dependent pathway in human endothelial cells. Cancer Res. 2002;62(19):5580-9.

82. Dhanabal M, Ramchandran R, Volk R, Stillman IE, Lombardo M, Iruela-Arispe ML, et al. Endostatin: yeast production, mutants, and antitumor effect in renal cell carcinoma. Cancer Res. 1999;59(1):189-97.

83. Olsson AK, Johansson I, Akerud H, Einarsson B, Christofferson R, Sasaki T, et al. The minimal active domain of endostatin is a heparinbinding motif that mediates inhibition of tumor vascularization. Cancer Res. 2004;64(24):9012-7.

84. O'Reilly MS, Boehm T, Shing Y, Fukai N, Vasios G, Lane WS, et al. Endostatin: an endogenous inhibitor of angiogenesis and tumor growth. Cell. 1997;88(2):277-85.

85. Hansen-Algenstaedt N, Stoll BR, Padera TP, Dolmans DE, Hicklin DJ, Fukumura D, et al. Tumor oxygenation in hormone-dependent tumors during vascular endothelial growth factor receptor-2 blockade, hormone ablation, and chemotherapy. Cancer Res. 2000;60(16):4556-60.

86. Helmlinger G, Endo M, Ferrara N, Hlatky L, Jain RK. Formation of endothelial cell networks. Nature. 2000;405(6783):139-41.

87. McKeown SR. Defining normoxia, physoxia and hypoxia in tumours-implications for treatment response. Br J Radiol. 2014;87(1035):20130676.

88. Eales KL, Hollinshead KE, Tennant DA. Hypoxia and metabolic adaptation of cancer cells. Oncogenesis. 2016;5:e190.

89. Ayob AZ, Ramasamy TS. Cancer stem cells as key drivers of tumour progression. J Biomed Sci. 2018;25(1):20.

90. Brahimi-Horn MC, Chiche J, Pouyssegur J. Hypoxia and cancer. J Mol Med (Berl). 2007;85(12):1301-7.

91. Harris AL. Hypoxia--a key regulatory factor in tumour growth. Nat Rev Cancer. 2002;2(1):38-47.

92. Ward JP. Oxygen sensors in context. Biochim Biophys Acta. 2008; 1777(1):1-14.

93. Semenza GL. Hypoxia-inducible factors in physiology and medicine. Cell. 2012;148(3):399-408.

94. Harada H, Inoue M, Itasaka S, Hirota K, Morinibu A, Shinomiya $\mathrm{K}$, et al. Cancer cells that survive radiation therapy acquire HIF-1 activity and translocate towards tumour blood vessels. Nat Commun. 2012;3:783.

95. Semenza GL. The hypoxic tumor microenvironment: A driving force for breast cancer progression. Biochim Biophys Acta. 2016;1863(3): 382-91.

96. Semenza GL. Targeting HIF-1 for cancer therapy. Nat Rev Cancer. 2003;3(10):721-32.

97. Lu X, Kang Y. Hypoxia and hypoxia-inducible factors: master regulators of metastasis. Clin Cancer Res. 2010;16(24):5928-35.

98. King HW, Michael MZ, Gleadle JM. Hypoxic enhancement of exosome release by breast cancer cells. BMC Cancer. 2012;12:421.

99. Shao C, Yang F, Miao S, Liu W, Wang C, Shu Y, et al. Role of hypoxiainduced exosomes in tumor biology. Mol Cancer. 2018;17(1):120.

100. Kosaka N, Iguchi H, Hagiwara K, Yoshioka Y, Takeshita F, Ochiya T. Neutral sphingomyelinase 2 (nSMase2)-dependent exosomal transfer of angiogenic microRNAs regulate cancer cell metastasis. J Biol Chem. 2013;288(15):10849-59.

101. Tadokoro H, Umezu T, Ohyashiki K, Hirano T, Ohyashiki JH. Exosomes derived from hypoxic leukemia cells enhance tube formation in endothelial cells. J Biol Chem. 2013;288(48):34343-51.

102. Umezu T, Tadokoro H, Azuma K, Yoshizawa S, Ohyashiki K, Ohyashiki JH. Exosomal miR-135b shed from hypoxic multiple myeloma cells enhances angiogenesis by targeting factor-inhibiting HIF-1. Blood. 2014;124(25):3748-57. 
103. Hsu YL, Hung JY, Chang WA, Lin YS, Pan YC, Tsai PH, et al. Hypoxic lung cancer-secreted exosomal miR-23a increased angiogenesis and vascular permeability by targeting prolyl hydroxylase and tight junction protein ZO-1. Oncogene. 2017;36(34):4929-42.

104. Mao G, Liu Y, Fang X, Liu Y, Fang L, Lin L, et al. Tumor-derived microRNA-494 promotes angiogenesis in non-small cell lung cancer. Angiogenesis. 2015;18(3):373-82.

105. Park JE, Tan HS, Datta A, Lai RC, Zhang H, Meng W, et al. Hypoxic tumor cell modulates its microenvironment to enhance angiogenic and metastatic potential by secretion of proteins and exosomes. $\mathrm{Mol}$ Cell Proteomics. 2010;9(6):1085-99.

106. Kore RA, Edmondson JL, Jenkins SV, Jamshidi-Parsian A, Dings RPM, Reyna NS, et al. Hypoxia-derived exosomes induce putative altered pathways in biosynthesis and ion regulatory channels in glioblastoma cells. Biochem Biophys Rep. 2018;14:104-13.

107. Skog J, Wurdinger T, van Rijn S, Meijer DH, Gainche L, Sena-Esteves $\mathrm{M}$, et al. Glioblastoma microvesicles transport RNA and proteins that promote tumour growth and provide diagnostic biomarkers. Nat Cell Biol. 2008;10(12):1470-6.

108. Kucharzewska P, Christianson HC, Welch JE, Svensson KJ, Fredlund E, Ringner M, et al. Exosomes reflect the hypoxic status of glioma cells and mediate hypoxia-dependent activation of vascular cells during tumor development. Proc Natl Acad Sci U S A. 2013;110(18):7312-7.

109. Milia AF, Salis MB, Stacca T, Pinna A, Madeddu P, Trevisani M, et al. Protease-activated receptor-2 stimulates angiogenesis and accelerates hemodynamic recovery in a mouse model of hindlimb ischemia. Circ Res. 2002;91(4):346-52.

110. Svensson KJ, Kucharzewska P, Christianson HC, Skold S, Lofstedt $\mathrm{T}$, Johansson MC, et al. Hypoxia triggers a proangiogenic pathway involving cancer cell microvesicles and PAR-2-mediated heparinbinding EGF signaling in endothelial cells. Proc Natl Acad Sci U S A. 2011;108(32):13147-52.

111. Huang Z, Feng Y. Exosomes Derived From Hypoxic Colorectal Cancer Cells Promote Angiogenesis Through Wnt4-Induced betaCatenin Signaling in Endothelial Cells. Oncol Res. 2017;25(5):651-61.

112. Sruthi TV, Edatt L, Raji GR, Kunhiraman H, Shankar SS, Shankar V, et al. Horizontal transfer of miR-23a from hypoxic tumor cell colonies can induce angiogenesis. J Cell Physiol. 2018;233(4):3498-514.

113. Grange C, Tapparo M, Collino F, Vitillo L, Damasco C, Deregibus $\mathrm{MC}$, et al. Microvesicles released from human renal cancer stem cells stimulate angiogenesis and formation of lung premetastatic niche. Cancer Res. 2011;71(15):5346-56.

114. Burnley-Hall N, Willis G, Davis J, Rees DA, James PE. Nitritederived nitric oxide reduces hypoxia-inducible factor lalphamediated extracellular vesicle production by endothelial cells. Nitric Oxide. 2017;63:1-12.

115. Zhang G, Zhang Y, Cheng S, Wu Z, Liu F, Zhang J. CD133 positive U87 glioblastoma cells-derived exosomal microRNAs in hypoxiaversus normoxia-microenviroment. J Neurooncol. 2017;135(1):37-46.

116. Luga V, Zhang L, Viloria-Petit AM, Ogunjimi AA, Inanlou MR, Chiu E, et al. Exosomes mediate stromal mobilization of autocrine Wnt-PCP signaling in breast cancer cell migration. Cell. 2012;151(7):1542-56.

117. Alvarez-Teijeiro S, Garcia-Inclan C, Villaronga MA, Casado P, Hermida-Prado F, Granda-Diaz R, et al. Factors Secreted by CancerAssociated Fibroblasts that Sustain Cancer Stem Properties in Head and Neck Squamous Carcinoma Cells as Potential Therapeutic Targets. Cancers (Basel). 2018;10(9).

118. Calvo F, Ege N, Grande-Garcia A, Hooper S, Jenkins RP, Chaudhry SI, et al. Mechanotransduction and YAP-dependent matrix remodelling is required for the generation and maintenance of cancer-associated fibroblasts. Nat Cell Biol. 2013;15(6):637-46.

119. Koczorowska MM, Tholen S, Bucher F, Lutz L, Kizhakkedathu JN, De Wever O, et al. Fibroblast activation protein-alpha, a stromal cell surface protease, shapes key features of cancer associated fibroblasts through proteome and degradome alterations. Mol Oncol. 2016;10(1):40-58.
120. Ramteke A, Ting H, Agarwal C, Mateen S, Somasagara R, Hussain A, et al. Exosomes secreted under hypoxia enhance invasiveness and stemness of prostate cancer cells by targeting adherens junction molecules. Mol Carcinog. 2015;54(7):554-65.

121. Fiaschi T, Giannoni E, Taddei ML, Cirri P, Marini A, Pintus G, et al. Carbonic anhydrase IX from cancer-associated fibroblasts drives epithelial-mesenchymal transition in prostate carcinoma cells. Cell Cycle. 2013;12(11):1791-801.

122. Giannoni E, Bianchini F, Masieri L, Serni S, Torre E, Calorini L, et al. Reciprocal activation of prostate cancer cells and cancer-associated fibroblasts stimulates epithelial-mesenchymal transition and cancer stemness. Cancer Res. 2010;70(17):6945-56.

123. Maia J, Caja S, Strano Moraes MC, Couto N, Costa-Silva B. ExosomeBased Cell-Cell Communication in the Tumor Microenvironment. Front Cell Dev Biol. 2018;6:18.

124. Carmeliet P, Jain RK. Angiogenesis in cancer and other diseases. Nature. 2000;407(6801):249-57.

125. Yoon YJ, Kim DK, Yoon CM, Park J, Kim YK, Roh TY, et al. Egr-1 activation by cancer-derived extracellular vesicles promotes endothelial cell migration via ERK1/2 and JNK signaling pathways. PLoS One. 2014;9(12):el15170.

126. Folkman J. Tumor angiogenesis: therapeutic implications. N Engl J Med. 1971;285(21):1182-6.

127. Song YH, Warncke C, Choi SJ, Choi S, Chiou AE, Ling L, et al. Breast cancer-derived extracellular vesicles stimulate myofibroblast differentiation and pro-angiogenic behavior of adipose stem cells. Matrix Biol. 2017;60-61:190-205.

128. Al-Nedawi K, Meehan B, Kerbel RS, Allison AC, Rak J. Endothelial expression of autocrine VEGF upon the uptake of tumor-derived microvesicles containing oncogenic EGFR. Proc Natl Acad Sci U S A. 2009;106(10):3794-9.

129. Conigliaro A, Costa V, Lo Dico A, Saieva L, Buccheri S, Dieli F, et al. CD90+ liver cancer cells modulate endothelial cell phenotype through the release of exosomes containing H19 lncRNA. Mol Cancer. 2015;14:155.

130.Dickman CT, Lawson J, Jabalee J, MacLellan SA, LePard NE, Bennewith KL, et al. Selective extracellular vesicle exclusion of miR$142-3 p$ by oral cancer cells promotes both internal and extracellular malignant phenotypes. Oncotarget. 2017;8(9):15252-66.

131. Lawson J, Dickman C, MacLellan S, Towle R, Jabalee J, Lam S, et al. Selective secretion of microRNAs from lung cancer cells via extracellular vesicles promotes CAMK1D-mediated tube formation in endothelial cells. Oncotarget. 2017;8(48):83913-24.

132. Schillaci O, Fontana S, Monteleone F, Taverna S, Di Bella MA, Di Vizio D, et al. Exosomes from metastatic cancer cells transfer amoeboid phenotype to non-metastatic cells and increase endothelial permeability: their emerging role in tumor heterogeneity. Sci Rep. 2017;7(1):4711.

133. Zhuang G, Wu X, Jiang Z, Kasman I, Yao J, Guan Y, et al. Tumoursecreted miR-9 promotes endothelial cell migration and angiogenesis by activating the JAK-STAT pathway. EMBO J. 2012;31(17):3513-23.

134. You B, Shan Y, Bao L, Chen J, Yang L, Zhang Q, et al. The biology and function of extracellular vesicles in nasopharyngeal carcinoma (Review). Int J Oncol. 2018;52(1):38-46.

135. Liu Y, Luo F, Wang B, Li H, Xu Y, Liu X, et al. STAT3-regulated exosomal miR-21 promotes angiogenesis and is involved in neoplastic processes of transformed human bronchial epithelial cells. Cancer Lett. 2016;370(1):125-35.

136.Zomer A, Maynard C, Verweij FJ, Kamermans A, Schafer R, Beerling E, et al. In Vivo imaging reveals extracellular vesicle-mediated phenocopying of metastatic behavior. Cell. 2015;161(5):1046-57.

137. Kosaka N. Decoding the Secret of Cancer by Means of Extracellular Vesicles. J Clin Med. 2016;5(2).

138. Abak A, Abhari A, Rahimzadeh S. Exosomes in cancer: small vesicular transporters for cancer progression and metastasis, biomarkers in cancer therapeutics. PeerJ. 2018;6:e4763.

139. Al-Nedawi K, Meehan B, Micallef J, Lhotak V, May L, Guha A, et al. Intercellular transfer of the oncogenic receptor EGFRvIII by microvesicles derived from tumour cells. Nat Cell Biol. 2008;10(5):619-24. 
140. Nazarenko I, Rana S, Baumann A, McAlear J, Hellwig A, Trendelenburg M, et al. Cell surface tetraspanin Tspan8 contributes to molecular pathways of exosome-induced endothelial cell activation. Cancer Res. 2010;70(4):1668-78.

141. Deregibus MC, Cantaluppi V, Calogero R, Lo Iacono M, Tetta C, Biancone L, et al. Endothelial progenitor cell derived microvesicles activate an angiogenic program in endothelial cells by a horizontal transfer of mRNA. Blood. 2007;110(7):2440-8.

142. Gesierich S, Berezovskiy I, Ryschich E, Zoller M. Systemic induction of the angiogenesis switch by the tetraspanin D6.1A/CO-029. Cancer Res. 2006;66(14):7083-94.

143. Thompson CA, Purushothaman A, Ramani VC, Vlodavsky I, Sanderson RD. Heparanase regulates secretion, composition, and function of tumor cell-derived exosomes. J Biol Chem. 2013;288(14):10093-9.

144. Hood JL, San RS, Wickline SA. Exosomes released by melanoma cells prepare sentinel lymph nodes for tumor metastasis. Cancer Res. 2011;71(11):3792-801.

145. Gajos-Michniewicz A, Duechler M, Czyz M. MiRNA in melanomaderived exosomes. Cancer Lett. 2014;347(1):29-37.

146. Umezu T, Ohyashiki K, Kuroda M, Ohyashiki JH. Leukemia cell to endothelial cell communication via exosomal miRNAs. Oncogene. 2013;32(22):2747-55.

147. Zhou W, Fong MY, Min Y, Somlo G, Liu L, Palomares MR, et al Cancer-secreted miR-105 destroys vascular endothelial barriers to promote metastasis. Cancer Cell. 2014;25(4):501-15.

148.Zitvogel L, Regnault A, Lozier A, Wolfers J, Flament C, Tenza $\mathrm{D}$, et al. Eradication of established murine tumors using a novel cell-free vaccine: dendritic cell-derived exosomes. Nat Med. 1998;4(5):594-600.

149. Tominaga N, Kosaka N, Ono M, Katsuda T, Yoshioka Y, Tamura K, et al. Brain metastatic cancer cells release microRNA-181ccontaining extracellular vesicles capable of destructing blood-brain barrier. Nat Commun. 2015;6:6716.

150. Treps L, Perret R, Edmond S, Ricard D, Gavard J. Glioblastoma stemlike cells secrete the pro-angiogenic VEGF-A factor in extracellular vesicles. J Extracell Vesicles. 2017;6(1):1359479.

151. Peinado H, Aleckovic M, Lavotshkin S, Matei I, Costa-Silva B, Moreno-Bueno G, et al. Melanoma exosomes educate bone marrow progenitor cells toward a pro-metastatic phenotype through MET. Nat Med. 2012;18(6):883-91.

152. Fabbri M, Paone A, Calore F, Galli R, Gaudio E, Santhanam R, et al. MicroRNAs bind to Toll-like receptors to induce prometastatic inflammatory response. Proc Natl Acad Sci U S A. 2012;109(31): E2110-6.

153. Jabalee J, Towle R, Garnis C. The Role of Extracellular Vesicles in Cancer: Cargo, Function, and Therapeutic Implications. Cells. 2018;7(8).

154.McCready J, Sims JD, Chan D, Jay DG. Secretion of extracellular hsp90alpha via exosomes increases cancer cell motility: a role for plasminogen activation. BMC Cancer. 2010;10:294.

155. Gopal SK, Greening DW, Hanssen EG, Zhu HJ, Simpson RJ, Mathias RA. Oncogenic epithelial cell-derived exosomes containing Racl and PAK2 induce angiogenesis in recipient endothelial cells. Oncotarget. 2016;7(15):19709-22.
156. Hood JL, Pan H, Lanza GM, Wickline SA, Consortium for Translational Research in Advanced I, Nanomedicine. Paracrine induction of endothelium by tumor exosomes. Lab Invest. 2009; 89(11):1317-28.

157. El-Kenawi AE, El-Remessy AB. Angiogenesis inhibitors in cancer therapy: mechanistic perspective on classification and treatment rationales. Br J Pharmacol. 2013;170(4):712-29.

158. Teicher BA. A systems approach to cancer therapy. (Antioncogenics + standard cytotoxics-->mechanism(s) of interaction). Cancer Metastasis Rev. 1996;15(2):247-72.

159. Kamba T, McDonald DM. Mechanisms of adverse effects of antiVEGF therapy for cancer. Br J Cancer. 2007;96(12):1788-95.

160. Ferrara N, Gerber HP, LeCouter J. The biology of VEGF and its receptors. Nat Med. 2003;9(6):669-76.

161. Gelinas DS, Bernatchez PN, Rollin S, Bazan NG, Sirois MG. Immediate and delayed VEGF-mediated NO synthesis in endothelial cells: role of PI3K, PKC and PLC pathways. Br J Pharmacol. 2002; 137(7):1021-30.

162. Hood JD, Meininger CJ, Ziche M, Granger HJ. VEGF upregulates ecNOS message, protein, and NO production in human endothelial cells. Am J Physiol. 1998;274(3 Pt 2):H1054-8.

163. Sane DC, Anton L, Brosnihan KB. Angiogenic growth factors and hypertension. Angiogenesis. 2004;7(3):193-201.

164. Bobrie A, Krumeich S, Reyal F, Recchi C, Moita LF, Seabra MC, et al. Rab27a supports exosome-dependent and -independent mechanisms that modify the tumor microenvironment and can promote tumor progression. Cancer Res. 2012;72(19):4920-30.

165. Nishida-Aoki N, Tominaga N, Takeshita F, Sonoda H, Yoshioka Y, Ochiya T. Disruption of Circulating Extracellular Vesicles as a Novel Therapeutic Strategy against Cancer Metastasis. Mol Ther. 2017;25(1):181-91.

166. Richards KE, Zeleniak AE, Fishel ML, Wu J, Littlepage LE, Hill R. Cancer-associated fibroblast exosomes regulate survival and proliferation of pancreatic cancer cells. Oncogene. 2017;36(13):1770-8.

167. Agarwal S, Muniyandi P, Maekawa T, Kumar DS. Vesicular systems employing natural substances as promising drug candidates for MMP inhibition in glioblastoma: A nanotechnological approach. Int J Pharm. 2018;551(1-2):339-61.

168. Keller S, Sanderson MP, Stoeck A, Altevogt P. Exosomes: from biogenesis and secretion to biological function. Immunol Lett. 2006; 107(2):102-8.

169. Krause M, Samoylenko A, Vainio SJ. Exosomes as renal inductive signals in health and disease, and their application as diagnostic markers and therapeutic agents. Front Cell Dev Biol. 2015;3:65.

170. Raposo G, Stoorvogel W. Extracellular vesicles: exosomes, microvesicles, and friends. J Cell Biol. 2013;200(4):373-83.

171. Simons M, Raposo G. Exosomes--vesicular carriers for intercellular communication. Curr Opin Cell Biol. 2009;21(4):575-81.

172.Zhang X, Yuan X, Shi H, Wu L, Qian H, Xu W. Exosomes in cancer: small particle, big player. J Hematol Oncol. 2015;8:83. 